\title{
Autoantigen TRIM21/Ro52 as a Possible Target for Treatment of Systemic Lupus Erythematosus
}

\author{
Ryusuke Yoshimi, ${ }^{1}$ Yoshiaki Ishigatsubo, ${ }^{1}$ and Keiko Ozato ${ }^{2}$ \\ ${ }^{1}$ Department of Internal Medicine and Clinical Immunology, Yokohama City University Graduate School of Medicine, \\ Yokohama 236-0004, Japan \\ ${ }^{2}$ Program in Genomics of Differentiation, National Institute of Child Health and Human Development, \\ National Institutes of Health, Bethesda, MD 20892, USA \\ Correspondence should be addressed to Ryusuke Yoshimi, yoshiryu@med.yokohama-cu.ac.jp
}

Received 11 January 2012; Revised 1 April 2012; Accepted 2 April 2012

Academic Editor: Javier Martin

Copyright (๑) 2012 Ryusuke Yoshimi et al. This is an open access article distributed under the Creative Commons Attribution License, which permits unrestricted use, distribution, and reproduction in any medium, provided the original work is properly cited.

\begin{abstract}
Systemic lupus erythematosus (SLE) is a chronic, systemic, and autoimmune disease, whose etiology is still unknown. Although there has been progress in the treatment of SLE through the use of glucocorticoid and immunosuppressive drugs, these drugs have limited efficacy and pose significant risks of toxicity. Moreover, prognosis of patients with SLE has remained difficult to assess. TRIM21/Ro52/SS-A1, a 52-kDa protein, is an autoantigen recognized by antibodies in sera of patients with SLE and Sjögren's syndrome (SS), another systemic autoimmune disease, and anti-TRIM21 antibodies have been used as a diagnostic marker for decades. TRIM21 belongs to the tripartite motif-containing (TRIM) super family, which has been found to play important roles in innate and acquired immunity. Recently, TRIM21 has been shown to be involved in both physiological immune responses and pathological autoimmune processes. For example, TRIM21 ubiquitylates proteins of the interferon-regulatory factor (IRF) family and regulates type I interferon and proinflammatory cytokines. In this paper, we summarize molecular features of TRIM21 revealed so far and discuss its potential as an attractive therapeutic target for SLE.
\end{abstract}

\section{Introduction}

Systemic lupus erythematosus (SLE) is a chronic, systemic, and autoimmune disease of unknown etiology. The disease is characterized by the presence of a variety of autoantibodies in patients' sera, including those specific for nuclear antigens called antinuclear antibodies (ANA). Although current therapies of SLE largely rely on glucocorticoids and immunosuppressant drugs, the efficacy is limited so far and there hold significant risks of toxicity. In order to better understand the pathogenesis and find new therapeutic designs, a systemic characterization of the molecular and cellular basis of signaling abnormalities in the immune system that lead to autoimmune response and inflammation is urgently required.

In sera of patients with SLE and Sjögren's syndrome (SS), another systemic autoimmune disease, an ANA specific for an autoantigen called Ro (also called SS-A) has been known since the 1960s [1-3]. While anti-Ro antibodies are found primarily in patients with SLE and SS, they are also sometimes seen in other systemic autoimmune diseases, such as systemic sclerosis, polymyositis/dermatomyositis, mixed connective tissue disease, and rheumatoid arthritis $[4,5]$. Although these anti-Ro antibodies have been used as a useful diagnostic marker for SLE and SS for decades, the molecular identity of Ro autoantigen had not been clarified for a long time. Later, Ro antigen was found to consist of two proteins, Ro52 (also called TRIM21, SSA1, or RNF81) and Ro60 (also called SSA2 or TROVE2), which seem to have functions not directly related to each other [6-8].

Anti-Ro antibodies have been reported to be associated with photosensitivity, subacute cutaneous lupus, cutaneous vasculitis, hematological disorder, interstitial lung disease, and neonatal lupus including congenital heart block [5, 915]. The anti-Ro antibodies are associated with the HLADR3 and/or DR2 haplotype and C4 complement component 
TABLE 1: SLE/SS-related SNP in TRIM21 gene.

\begin{tabular}{|c|c|c|c|c|c|c|}
\hline \multirow{3}{*}{$\begin{array}{l}\text { Location (position)* } \\
5^{\prime} \text {-UTR } \\
(4595)\end{array}$} & \multirow{3}{*}{$\begin{array}{c}\text { Reference SNP ID } \\
\text { rs5030767 }\end{array}$} & \multirow[t]{3}{*}{ Nucleotide change } & \multicolumn{2}{|c|}{ Genotype frequency (\%) } & \multirow[t]{3}{*}{$P$ Value } & \multirow[t]{3}{*}{ Reference } \\
\hline & & & $\mathrm{Ab}(+) \mathrm{pSS}$ & $\mathrm{HC}$ & & \\
\hline & & & $(n=38)$ & $(n=72)$ & & \\
\hline & & $\mathrm{C} / \mathrm{C}$ & 60.5 & 83.3 & 0.029 & [22] \\
\hline & & $\mathrm{C} / \mathrm{T}$ & 34.2 & 13.9 & & \\
\hline & & $\mathrm{T} / \mathrm{T}$ & 5.3 & 2.8 & & \\
\hline \multirow{5}{*}{$\begin{array}{l}\text { Intron } 1 \\
(7216)\end{array}$} & rs7947461 & & $\mathrm{Ab}(+) \mathrm{pSS}$ & $\mathrm{Ab}(-) \mathrm{pSS}$ & & \\
\hline & & & $(n=39)$ & $(n=23)$ & & \\
\hline & & $\mathrm{A} / \mathrm{A}$ & 25.6 & 4.3 & 0.028 & [23] \\
\hline & & $\mathrm{A} / \mathrm{G}$ & 56.4 & 52.2 & & \\
\hline & & $\mathrm{G} / \mathrm{G}$ & 17.9 & 43.5 & & \\
\hline \multirow{5}{*}{$\begin{array}{l}\text { Intron } 1 \\
(7219)\end{array}$} & rs660 & & SLE & $\mathrm{HC}$ & & \\
\hline & & & $(n=26)$ & $(n=29)$ & & \\
\hline & & $\mathrm{C} / \mathrm{C}$ & 3.8 & 34.5 & $<0.0005$ & {$[20,21]$} \\
\hline & & $\mathrm{C} / \mathrm{T}$ & 26.9 & 44.8 & & \\
\hline & & $\mathrm{T} / \mathrm{T}$ & 69.2 & 20.7 & & \\
\hline \multirow{5}{*}{$\begin{array}{l}\text { Intron } 1 \\
(7649)\end{array}$} & rs5030768 & & $\mathrm{Ab}(+) \mathrm{pSS}$ & $\mathrm{HC}$ & & \\
\hline & & & $(n=38)$ & $(n=72)$ & & \\
\hline & & $\mathrm{A} / \mathrm{A}$ & 57.9 & 80.5 & 0.038 & {$[22]$} \\
\hline & & $\mathrm{A} / \mathrm{G}$ & 34.2 & 16.7 & & \\
\hline & & $\mathrm{G} / \mathrm{G}$ & 7.9 & 2.8 & & \\
\hline \multirow{5}{*}{$\begin{array}{l}\text { Intron } 3 \\
(9571)\end{array}$} & rs915956 & & $\mathrm{Ab}(+) \mathrm{pSS}$ & $\mathrm{HC}$ & & \\
\hline & & & $(n=38)$ & $(n=72)$ & & \\
\hline & & $\mathrm{C} / \mathrm{C}$ & 44.7 & 84.7 & 0.00003 & [22] \\
\hline & & $\mathrm{C} / \mathrm{T}$ & 52.6 & 12.5 & & \\
\hline & & $\mathrm{T} / \mathrm{T}$ & 2.6 & 2.8 & & \\
\hline \multirow{4}{*}{$\begin{array}{l}3^{\prime}-\text { UTR } \\
(12986)\end{array}$} & rs4144331 & & $\mathrm{Ab}(+) \mathrm{pSS}$ & $\mathrm{HC}$ & & \\
\hline & & & $(n=38)$ & $(n=72)$ & & \\
\hline & & $\mathrm{C} / \mathrm{C}$ & 71.1 & 87.5 & 0.033 & [22] \\
\hline & & $\mathrm{C} / \mathrm{A}$ & 28.9 & 12.5 & & \\
\hline
\end{tabular}

* Position in the gene according to GenBank accession no. UO1882. UTR, untranslated region; Ab(+), anti-TRIM21 antibody-positive; pSS, primary SS, HC, healthy control; $\mathrm{Ab}(-)$, anti-TRIM21 antibody-negative.

deficiency [16, 17]. Among the anti-Ro antibodies, antiTRIM21/Ro52 antibodies have been used for diagnosis and monitoring and have been shown to act as a pathological factor $[18,19]$.

The TRIM21 gene has also been linked to the diseases, although the sample numbers were small in the reported studies. These studies suggest possible associations between allelic polymorphisms of TRIM21 and the disease susceptibility and increased anti-TRIM21 antibodies in SLE and SS (Table 1). The rs660 C/T single-nucleotide polymorphism (SNP) has been shown to be associated with SLE in African Americans [20, 21]. In this SNP, population size of $\mathrm{rs} 660 \mathrm{C} / \mathrm{C}$ in patients with SLE was around one ninth of that in healthy controls. The rs5030767 C/T, rs5030768 A/G, rs915956 C/T, and rs4144331 C/A SNPs were shown to be associated with anti-TRIM21 antibody-positive primary SS in a Norwegian population, among which rs915956 shows the strongest association [22]. Population size of rs915956C/C in antiTRIM21 antibody-positive patients with SS was about one half of that in healthy controls. The rs7947461 A/G SNP is one of genetic factors involved in Japanese SS [23]. rs7947461A/A population in anti-TRIM21 antibody-positive patients with SS was six times as large as that in anti-TRIM21 antibody-negative patients.

Furthermore, about a twofold increase in the expression of TRIM21 transcripts in peripheral blood mononuclear cells (PBMC) of patients with SLE and SS as compared with healthy controls has been reported, although data on protein levels was not shown [24]. Thus, not only the antibodies to TRIM21 but also the TRIM21 antigen itself has been suggested to have a role, in some way, in the pathogenesis of SLE and SS [25]. In this paper, we focus on the nature and function of the TRIM21 molecule and discuss its potential as a therapeutic target of systemic autoimmune diseases. 


\section{The TRIM21 Gene Locus, Molecular Structure, and Expression Pattern}

In 1991, two independent groups cloned the cDNA of human TRIM21, a 475-aa and 52-kDa protein [26, 27]. Subsequently, the human TRIM21 gene was mapped to the region $11 \mathrm{p} 15.5$ on chromosome 11 and the exon-intron structure was clarified $[20,28,29]$. The murine homologue, Trim21, has also been cloned [30]. The amino acid sequence identity between the murine and the human TRIM21 proteins is $69.9 \%$, and when conservative substitutions were taken into account, the similarly increases to $81.5 \%$. The identity is much higher in regions containing predicted functional domains [30]. The TRIM21 gene is $8.8 \mathrm{~kb}$ (in human) or $7.5 \mathrm{~kb}$ (in mouse) in size, consisting of 7 (in human) or 8 (in mouse) exons with conserved exon-intron structure. There are two large regions of closely related TRIM gene clusters in the human and murine genomes [31]. First, TRIM10, TRIM15, TRIM26, TRIM31, TRIM39, and TRIM40 are located in the major histocompatibility complex region on chromosome 6 in human and 17 in mouse. Second, TRIM3, TRIM5, TRIM6, TRIM21, TRIM22, TRIM34, TRIM66, and TRIM68 are located on chromosome 11 in human and 7 in mouse.

The TRIM21 protein belongs to the tripartite motifcontaining (TRIM) superfamily by its molecular structure $[32,33]$. A common structural feature of the TRIM superfamily is the highly conserved RBCC motif, containing the RING, B-box, and coiled-coil domains in this order $[31,34]$. TRIM proteins exhibit a wide range of activities, including the regulation of innate and adaptive immunity [33]. Interestingly, TRIM68, encoded by a gene that is adjacent to TRIM21, has a structure that is similar to TRIM21. TRIM68 is another autoantigen, SS-56, found in patients with SLE and SS [35]. The N terminus of TRIM21 has the RING domain (aa 15-58 in human) with two $\mathrm{Zn}^{2+}$ binding sites and the B-box domain (aa 91-128) with one $\mathrm{Zn}^{2+}$-binding site [26]. The middle part of the protein, which includes the leucine zipper, has a coiled-coil structure (aa 125-235). The $\mathrm{C}$ terminus of TRIM21 contains a PRYSPRY domain (aa 286-465; also referred to as B30.2) also found in many other TRIM proteins [36, 37].

TRIM21 is expressed ubiquitously as determined by in situ hybridization [32, 38-41]. Recently, more precise distribution patterns were analyzed for TRIM21 using Trim21-null mice with an enhanced green fluorescent protein (EGFP) reporter gene by two independent groups [42, 43]. TRIM21 is expressed at the highest levels in immune organs, such as lymph nodes, spleen and thymus in the mice. Among leukocyte subsets, TRIM21 expression is generally high in T cells, natural killer $\mathrm{T}$ cells, and macrophages and dendritic cells, but lower in B cells and granulocytes, although the levels varied for cells in each type [42]. For example, among B cell subsets, B-1a cells expressed TRIM21 levels twice that of plasma cells. Within dendritic cell (DC) subsets, TRIM21 levels were higher in the conventional DCs (cDCs) than plasmacytoid DCs (pDCs).

TRIM21 expression levels vary substantially during the early development of both the B and $\mathrm{T}$ cell lineages [42]. As for intracellular localization, TRIM21 mostly resides in the cytoplasm, although low levels are also found in the nucleus $[44,45]$. A study with overexpressed recombinant GFPTRIM21 fusion protein showed that full-length TRIM21 is almost exclusively localized in the cytoplasm while deletion mutants lacking the coiled-coil domain spread evenly throughout the cell, suggesting that the cytoplasmic localization of TRIM21 is mediated by the coiled-coil region [46]. In the cytoplasm, TRIM21 has been shown to localize in unidentified distinct structures called "cytoplasmic body," which is located along the microtubule network [32, 47, 48].

TRIM21 has been extensively documented as an interferon- (IFN-) inducible protein in various cell types [41-43, 47, 49-52]. TRIM21 is also induced by viral infection or Toll-like receptor (TLR) engagement via type I IFN induction $[42,50,53]$. TRIM21 is translocated from the cytoplasm into the nucleus upon IFN- $\alpha$ stimulation $[47,50]$. On the other hand, TRIM21 translocation in the cell is also mediated by other stimulations. It has been reported that TRIM21 translocates from the cytoplasm to cell surface in apoptotic or stressed cells. TRIM21 is translocated to apoptotic blebs and associated with the plasma membrane in apoptotic endothelial cells [54]. A similar translocation has also been demonstrated in apoptotic fetal cardiomyocytes $[55,56]$. In keratinocytes, TRIM 21 is translocated from the cytoplasm to the cell surface in response to UV light, oxidative stress, nitric oxide (NO) or estradiol treatment [57-62]. TRIM21 expression has also been reported to be elevated in the brain microvasculature, which may be related to brain vascular involvement in autoimmune diseases [63].

TRIM21 has an alternative splicing variant, named Ro52 $\beta$. The entire exon 4, comprising the C-terminal part of the coiled-coil domain, is spliced off in Ro52 $\beta$. So far Ro52 $\beta$ has been detected only at the mRNA level and to date there is no report showing the Ro52 $\beta$ protein, with the predicted molecular weight of $45 \mathrm{kDa}[28,64]$. Ro52 $\beta$ transcript levels are markedly increased in human fetal hearts between 14 weeks and 16 weeks of gestation and diminish at 22-25 weeks [64]. The expression levels of the two splicing variants have been investigated also in salivary glands of patients with SS, but no significant difference in the levels of either variant between patients and healthy controls has been detected in this paper [65].

\section{TRIM21 Functions}

The RING domains of TRIM family members have been shown to have E3 ubiquitin ligase activity, which mediates ubiquitylation events [33]. Following the first demonstration of TRIM21 ubiquitin E3 ligase activity by Wada et al., several reports supporting the conclusion have been published by other groups $[24,38,41,66]$.

There have been many papers reporting TRIM21interacting proteins (Table 2 ). IFN regulatory factors (IRFs), a family of transcription factors that stimulates transcription of type I IFN and other immune response genes after activation, have been shown to be substrates of the TRIM21 ubiquitin ligase. TRIM21 interacts with IRF8, following stimulation by IFN and TLR ligands, suggesting a role for 
TABLE 2: TRIM21-binding proteins.

\begin{tabular}{|c|c|c|c|}
\hline Protein & Molecular function of TRIM21 & Functional output & Reference \\
\hline \multicolumn{4}{|c|}{ (1) Substrate of TRIM21 E3 ligase } \\
\hline IRF3 & Proteasomal degradation & Suppressing IFN- $\beta$ production & {$[68]$} \\
\hline IRF7 & Proteasomal degradation & Suppressing IFN- $\alpha$ production & {$[70]$} \\
\hline IRF8 & Transcriptional activation & Promoting IL-12p40 production & {$[41]$} \\
\hline $\operatorname{IgG}$ & Proteasomal degradation & Neutralization of IgG-coated virion & {$[82]$} \\
\hline $\mathrm{IKK} \beta$ & Translocation to autophagosomes & Suppressing NF- $\kappa$ B signaling & {$[91]$} \\
\hline UnpEL & Unknown & Unknown & [39] \\
\hline TRIM $5 \alpha$ & Translocation to cytoplasm & Unknown & [111] \\
\hline \multicolumn{4}{|c|}{ (2) Proteins supporting TRIM21 E3 activity } \\
\hline Skp2 & Facilitating p27 degradation & Promoting S-phase progression & {$[38]$} \\
\hline Skp1 & Facilitating p27 degradation & Promoting S-phase progression & {$[38]$} \\
\hline Cull & Facilitating p27 degradation & Promoting S-phase progression & {$[38]$} \\
\hline$\beta \operatorname{TrCP} 2$ & Unknown & Unknown & {$[38]$} \\
\hline p62 & Facilitating IRF8 degradation & Suppressing IL-12p40 production & {$[67]$} \\
\hline TRIB2 & Facilitating $\mathrm{C} / \mathrm{EBP} \alpha$ degradation & Promoting lung tumorigenesis & {$[85]$} \\
\hline FADD & Facilitating IRF7 degradation & Suppressing IFN- $\alpha$ production & {$[71]$} \\
\hline \multicolumn{4}{|c|}{ (3) Proteins irrelevant to TRIM21 E3 activity } \\
\hline IRF3 & Stabilization & Promoting IFN- $\beta$ production & {$[69]$} \\
\hline $\operatorname{Daxx}$ & Unknown & Unknown & {$[84]$} \\
\hline Flash & Translocating Daxx to cytoplasm & Unknown & {$[84]$} \\
\hline $\mathrm{DCP} 2$ & Facilitating decapping activity & Unknown & {$[86]$} \\
\hline
\end{tabular}

this protein in innate immunity [41]. This interaction, which occurs in the nucleus, mediates IRF8 ubiquitylation and increases the ability of IRF8 to promote interleukin (IL)-12p40 transcription in murine macrophage cell line. Later, sequestosome 1 (also called p62), an adaptor protein with multiple functions, was also shown to interact with TRIM21 and IRF8, which leads to increased polyubiquitylation and destabilization of IRF8 in stimulated macrophages, resulting in attenuation of IL-12p40 expression [67]. There are two contradictory reports as to the role of TRIM21 in IRF3 ubiquitylation. One group reported that TRIM21 ubiquitylates IRF3 following TLR3 or TLR4 stimulation, which leads to its degradation at proteasome, resulting in negative regulation of type I IFN [68]. Another group showed that TRIM21 stabilizes IRF3 by interfering with the interaction between peptidyl-prolyl cis/trans isomerase, NIMA-interacting 1 (Pin1), and IRF3, thus enhancing the strength and duration of primary antiviral response [69]. TRIM21-mediated IRF7 ubiquitylation promotes the degradation of IRF7 following TLR7 or TLR9 stimulation, resulting in a decrease of IFN- $\alpha$ production [70]. It is also reported that Fas-associated death domain (FADD) and TRIM21 cooperatively ubiquitylate IRF7, interfere with the ubiquitin ligase activity of TNF receptor-associated factor 6 (TRAF6) by affecting phosphorylation status of IRF7, and repress IFN- $\alpha$ activation in Sendai virus-infected cells [71]. Characterization of immune cells from TRIM21-deficient mice demonstrated that TRIM21 is required for polyubiquitylation and degradation of IRF5 in addition to IRF3, IRF7, and IRF8, although interaction between TRIM21 and IRF5 has not shown yet $[42,43,70]$. In sum, although the role of TRIM21 in regulating the IFN pathway is still controversial, multiple lines of evidence strongly suggest that TRIM21 is an important regulator in innate immune responses.

TRIM21 may also have important roles in acquired immunity. TRIM21 may regulate T-cell activation or proliferation, since overexpression of TRIM21 has been shown to increase IL-2 production in CD28-stimulated Jurkat T cells [72]. Reduced IL-2 results in the suppression of activationinduced cell death and increased longevity of autoreactive $\mathrm{T}$ cells in patients with SLE [73]. In a murine B-cell line, TRIM21 negatively regulates cell growth in steady state and increases apoptotic cell death after activation via the CD40 pathway [24]. Based on the antigen-driven immune response hypothesis, the produced apoptotic cell debris, which could be the source of TRIM21 autoantigen, may induce the production of anti-TRIM21 antibodies [74]. These autoantibodies could cause the subsequent inflammatory condition and create a positive feedback amplification loop of inflammation. Additionally, it also suggests that the increased expression of the TRIM21 autoantigen in patients may be directly involved in the reduced cellular proliferation and increased apoptotic cell death observed in SLE and SS.

Another protein that has been well investigated as a TRIM21-binding protein is IgG [75-80]. The interaction was first suspected from the unexpected observation that normal human sera could precipitate TRIM21 [81]. Then several groups reported that TRIM21 binds to the Fc region of human $\operatorname{IgG}_{1}, \operatorname{IgG}_{2}$, and $\operatorname{IgG}_{4}$ via the PRYSPRY domain with high affinity $(K d=37 \mathrm{nM})[76,78,80]$. The PRYSPRY 
domain binds to different parts of the IgG Fc region from where Fc $\gamma$ R binds to. On the other hand, human TRIM21 does not seem to interact with murine IgG [80]. Although the physiological meaning of TRIM21-IgG interactions remains unknown, it may play a role in the pathogenesis of SLE and SS. Recently, Mallery et al. reported that TRIM21 rapidly recruits incoming antibody-coated virus and targets it to the proteasome via its E3 ubiquitin ligase activity, resulting in degradation of virions in the cytosol [82]. Infection experiments demonstrate that at physiological antibody concentrations TRIM21 neutralizes viral infection. Based on these data, the authors suggest a new interesting concept that antibodies mediate an intracellular immune response and protect cell interior and that TRIM21 acts as an intracellular antibody receptor for the ubiquitin-proteasome system [83]. Nevertheless, it remains unclear how the proteasome deals with such a large substrate as the viral capsid.

TRIM21 has been shown to interact with several additional proteins. The TRIM21-Skp2-SKp1-Cul1 complex ubiquitylates and degrades the cyclin-dependent kinase inhibitor p27 and promotes S-phase progression in human cell line [38]. TRIM21 associates with the apoptosis-related proteins, Daxx and FLASH, and induces cytoplasmic localization of Daxx in cooperation with FLASH [84]. TRIM21 interacts with tribbles homolog 2 (TRIB2) and leads to degradation of a differentiation-inducing transcription factor CCAAT/enhancer-binding protein $\alpha(\mathrm{C} / \mathrm{EBP} \alpha)$, causing lung tumorigenesis [85]. TRIM21 binds to and activates decapping enzyme 2 (DCP2), suggesting a role in mRNA metabolism in response to cellular stimulation [86].

The rs660 polymorphism in TRIM21 correlates with the age at which patients with sickle cell disease become alloimmunized following red blood cell (RBC) transfusion [87]. Because this polymorphism is found outside of the TRIM21-coding regions, it has been proposed to play a role in regulating levels of TRIM21 expression [20,87]. Thus, it has been hypothesized that rs660C/T leads to lower levels of TRIM21 expression than $\mathrm{rs} 660 \mathrm{~T} / \mathrm{T}$, resulting in reduced negative feedback responses and higher rates of alloimmunization against transfused RBCs. However, depletion of TRIM21 expression did not enhance transfusion-induced humoral alloimmunization in murine model [88].

How do autoantibodies to TRIM21 in sera affect the function of TRIM21 inside cells? First, it should be clarified how autoantibodies meet intracellular TRIM21 molecules. Recently, it has been reported that IgG can enter the cytoplasm of nonimmune cells through the cell membrane together with virus [82]. This suggests the possibility of intracellular autoantigen-autoantibody interaction. Second, we should know the effect of autoantigen-autoantibody interaction on the molecular function of TRIM21. A recent report shows that anti-TRIM21 autoantibodies inhibit the E3 ligase activity of TRIM21 by sterically blocking the E2/E3 interaction between TRIM21 and UBE2E1 [89]. Although it still remains to be investigated whether enough antiTRIM21 autoantibodies can enter cells to inhibit TRIM21 function sufficiently, this inhibition may contribute to the pathogenesis of SLE and SS by inhibiting TRIM21-mediated ubiquitylation.

\section{Trim21-Knockout Mice}

Two groups have recently disrupted the murine Trim 21 gene for analyses of TRIM21 function [42, 43]. They reported markedly different phenotypes for their mutant mice, although there are some similarities. The Trim $21^{-1-}$ mice described by Yoshimi et al. live a normal life span with no overt abnormal phenotypes [42]. Their immune cells show normal composition and elicit comparable responses to pathogen signals and antigen stimulation as cells of wildtype mice. In addition, Yoshimi et al. noted about a twofold increase in production of NF- $\kappa \mathrm{B}$-dependent cytokines, such as IL- $1 \beta, \operatorname{TNF} \alpha$, and IL-6, was observed in $\operatorname{Tr} \operatorname{im} 21^{-/-}$ fibroblasts as compared to wild-type fibroblasts. Data consistent with this paper were published by another group $[90,91]$. That is, TRIM 21 downregulates NF- $\kappa \mathrm{B}$ signalling by monoubiquitylating $\mathrm{I} \kappa \mathrm{B}$ kinase $\beta(\mathrm{IKK} \beta)$ and translocating IKK $\beta$ to autophagosomes. Several Trim genes, Trim12, Trim30, or Trim34, encoded near Trim21 were found upregulated in Trim $21^{-/-}$cells, suggesting that the absence of TRIM21 protein in these mice was compensated by a network of cross-talk among related TRIM members.

On the other hand, Espinosa et al. reported that TRIM21-deficient mice develop uncontrolled inflammation and systemic autoimmunity as a consequence of minor tissue injury caused by ear tagging [43]. However the mutant mice still carried a C-terminally truncated Trim 21 and expressed the corresponding transcript $[92,93]$. In these mice, the general autoimmune pathology and neutrophil recruitment to the site of injury were IL-23 dependent, as they were not observed when the mice were crossed to IL-23p19-deficient mice. Bone-marrow-derived macrophages and splenocytes from the mutant mice released more inflammatory cytokines, IL-6, TNF $\alpha$, type I IFN, and IL-23, upon TLR activation as compared to wild type. Overall, these data demonstrate that TRIM21 is induced by IFN activation of immune cells, where it acts as a negative regulator of IFN signaling.

Although the possibility that differences in environmental factors between the colonies of the two laboratories could account for the discrepancies cannot be ruled out, there are marked differences in the gene disruption method used by the two groups [92, 93]. First, in mice made by Espinosa et al. the overexpressed truncated protein could act as a dominant negative mutant, interfering with the function of a number of TRIM family members, including the normal TRIM21, and resulting in a stronger phenotype than the null mutant reported by Yoshimi et al. Second, the mutant mice reported by Espinosa et al. did not show a compensatory increase in the expression of other Trim genes as observed in the null mutant, suggesting that the stronger phenotype is due to a lack of the compensatory mechanisms. Anyway, the results from these two mutant mice suggest that TRIM21 is a negative regulator for proinflammatory cytokine production. Further experiments using animal disease models are needed for pursuing the proposed use of TRIM21 as a therapeutic target in the future. For example, it will be interesting to investigate whether disease severity of murine lupus model strains, such as MRL/lpr, BWF1, and B6-Yaa, can be diminished by adenovirus-mediated Trim 21 gene transfer. 


\section{TRIM21 as a Possible Therapeutic Target for SLE}

Patients with SLE are usually treated with nonsteroidal antiinflammatory drugs (NSAIDs), glucocorticoids, antimalarials, and immunosuppressants, including cyclophosphamide, azathioprine, mycophenolate mofetil, cyclosporine, tacrolimus, and methotrexate. Owing to the use of these drugs, the prognosis of patients with SLE has dramatically improved in the past. Nonetheless, rheumatologists sometimes encounter cases in which it is difficult to control the disease activity or to continue the treatment due to serious side effects.

In patients with SLE, increased expression of a subset of IFN-inducible genes, collectively called "interferon signature," is often observed [94]. Thus, the high level of type I IFN and IFN-stimulated genes has been suspected to be involved in the pathogenesis of SLE. pDCs produce a large amount of type I IFN via the activation of TLR7 and TLR9 upon viral infection, and these cells are thought to be the main source of IFN- $\alpha$ in patients with SLE $[95,96]$. While the number of $\mathrm{pDC}$ is reduced in the peripheral blood, many pDCs infiltrate into the skin and renal lesions in patients with SLE [97]. The serum levels of IFN are high in a subset of SLE patients and correlate with the disease activity [98]. IFN therapy of hepatitis C can lead to SLE as a side effect [99]. Thus suppression of IFN signaling can be a hopeful strategy for SLE treatment. TRIM21 negatively controls type I IFN production via ubiquitylation of IRFs as discussed above. Because TRIM21 expression is increased by type I IFN, the role of TRIM21 as a negative regulator increases late after inflammation. Thus, TRIM21 could repress and turn off type I IFN production, contributing to protection from prolonged overproduction of type I IFN and the pathogenesis of SLE. Therefore, increasing E3 activity of TRIM21 in type IFNproducing cells, such as pDCs and fibroblasts, may also be a useful strategy for the treatment of SLE.

NF- $\kappa$ B plays a pivotal role in inflammation through its ability to induce transcription of proinflammatory cytokines, chemokines, and adhesion molecules [100]. In SLE, for example, in situ expression of activated NF- $\kappa \mathrm{B}$ is increased in glomerular endothelial cells, mesangial cells, and infiltrating cells in class IV lupus nephritis, along with upregulation of TNF $\alpha$, IL-1 $\beta$, IL-6, and ICAM-1 expression [101]. Some of the effects of glucocorticoids used in SLE treatment are mediated through the inhibition of NF- $\kappa \mathrm{B}$ activation. The NF- $\kappa \mathrm{B}$ activation is mediated by IKK via phosphorylation of I $\kappa \mathrm{B}$. TRIM 21 downregulates NF- $\kappa \mathrm{B}$ signalling by monoubiquitylating IKK $\beta$, a subunit of IKK complex, and translocating IKK $\beta$ to autophagosomes [42, 90, 91]. Because TRIM21 expression is increased by type I IFN as noted above, the activity of TRIM 21 in inhibiting NF- $\kappa \mathrm{B}$ signalling can augment at a late phase in inflammation. Thus, TRIM21 could have an essential physiological role in turning off the NF- $\kappa$ B signalling, avoiding prolonged overproduction of proinflammatory cytokines, chemokines, and adhesion molecules. Therefore, a strategy for increasing E3 activity of TRIM21 in macrophages and in many cell types may also be useful for the treatment of SLE.
TRIM21 is substantially induced by type I IFN, type II IFN, and TLR ligands in DCs, macrophages, and fibroblasts. This implies the physiological significance of TRIM21 in an inflammatory state in these cells. Thus, increasing the expression of TRIM21 in these cells can be of advantage to the patients. Additionally, T cells may be an important subset for the therapy targeting TRIM21, because TRIM21 is highly expressed in T cells among leukocyte subsets, suggesting the significance of TRIM21 in T cells. Serum IL-2 levels are reduced in patients with SLE, resulting in the suppression of activation-induced cell death and increased life-span of autoreactive T cells [73]. This also likely causes an increased risk of infection, one of the major prognosis factors for SLE [73]. Because TRIM21 seems to positively regulate IL2 production by T cells [72], increasing TRIM 21 activity in T cells may be a strategy worthy of consideration.

Differentiation of T-cell subsets is biased in patients with SLE. Increased IL-6 production by antigen presenting cells and decreased IL-2 secretion by T cells inhibit the development of regulatory $\mathrm{T}$ cells and promote the differentiation of IL-17-producing T (Th17) cells. Given that Th17 cells are found not only in the peripheral blood but also in the inflamed kidney in patients with SLE $[102,103]$, blockade of IL-17 or IL-23, which is important for IL-17 production by Th17 cells, may help to control SLE pathogenesis. As TRIM21 can negatively regulate IL-23-Th17 pathway [43], increased E3 activity by TRIM21 may contribute to the regulation of these cytokines.

In order to suppress aberrant antibody production, modulating the number and the function of $\mathrm{B}$ cells has been regarded as a promising means for controlling SLE. Although small studies and case series using a chimeric anti-CD20 antibody, rituximab, in patients with SLE have initially shown promising data [104-106], a placebo-controlled randomized trial of rituximab in patients with moderate-to-severe SLE failed to observe efficacy of rituximab [107]. Belimumab, a human monoclonal antibody that neutralizes a B-cell survival factor, B-lymphocyte stimulator (BLyS), has received an FDA approval for the treatment of patients with active, autoantibody-positive SLE receiving standard therapy [108]. Because TRIM21 is suggested to negatively regulate B-cell growth and increase apoptotic cell death [24], it may be effective as a B-cell-based treatment of SLE. However, there is also a possibility that increased apoptotic death in B cells may exacerbate the pathogenesis of SLE. On the other hand, increased IL-6 promotes antibody production in humans and mice with lupus [109]. A monoclonal antibody against the IL-6 receptor, tocilizumab, has been reported to be promising in a phase I clinical trial [110]. TRIM21 may suppress antibody production by suppressing IL-6 production.

In sum, increasing the activity of TRIM 21 could be beneficial in controlling many aspects of SLE disease activity. Although altering the broad range of activity by TRIM21 could suggest potential risk of a variety of side effects, TRIM21-targeting therapy may provide a new avenue of SLE treatment, which may offer multiple benefits unattainable by existing therapies. 


\section{Conclusions}

SLE is an autoimmune disease, in which immune system aberrations as well as heritable, hormonal, and environmental factors contribute to the manifestation of organ damage. Recent data suggest that the autoantigen TRIM21 negatively regulates the development of autoimmune diseases and inflammation in autoimmune pathogenesis. Thus, TRIM21targeted therapy may offer a useful new strategy for treating autoimmune diseases.

\section{Conflict of Interests}

The authors have no financial conflict of interest.

\section{Acknowledgments}

The authors thank Mr. Tom Kiper for his review of the paper. This paper was supported by Research Grants from Japan Society for the Promotion of Science KAKENHI (no. 23791118) (R. Yoshimi), Japan Rheumatism Foundation (R. Yoshimi) and Yokohama Academic Foundation (R. Yoshimi). This paper was also supported partly by the Intramural Program of NICHD, National Institutes of Health, USA.

\section{References}

[1] G. Clark, M. Reichlin, and T. B. Tomasi Jr, "Characterization of a soluble cytoplasmic antigen reactive with sera from patients with systemic lupus erythmatosus," Journal of Immunology, vol. 102, no. 1, pp. 117-122, 1969.

[2] M. Mattioli and M. Reichlin, "Heterogeneity of RNA protein antigens reactive with sera of patients with systemic lupus erythematosus. Description of a cytoplasmic nonribosomal antigen," Arthritis and Rheumatism, vol. 17, no. 4, pp. 421429, 1974.

[3] M. A. Alspaugh and E. M. Tan, "Antibodies to cellular antigens in Sjogren's syndrome," Journal of Clinical Investigation, vol. 55, no. 5, pp. 1067-1073, 1975.

[4] J. Schulte-Pelkum, M. Fritzler, and M. Mahler, "Latest update on the Ro/SS-A autoantibody system," Autoimmunity Reviews, vol. 8, no. 7, pp. 632-637, 2009.

[5] P. Ghillani, C. André, C. Toly et al., "Clinical significance of anti-Ro52 (TRIM21) antibodies non-associated with antiSSA $60 \kappa \mathrm{Da}$ antibodies: results of a multicentric study," Autoimmunity Reviews, vol. 10, no. 9, pp. 509-513, 2011.

[6] E. Ben-Chetrit, E. K. L. Chan, K. F. Sullivan, and E. M. Tan, "A $52-\kappa \mathrm{D}$ protein is a novel component of the SS-A/Ro antigenic particle," Journal of Experimental Medicine, vol. 167, no. 5, pp. 1560-1571, 1988.

[7] S. L. Wolin and J. A. Steitz, "The Ro small cytoplasmic ribonucleoproteins: identification of the antigenic protein and its binding site on the Ro RNAs," Proceedings of the National Academy of Sciences of the United States of America, vol. 81, no. 7, pp. 1996-2000, 1984.

[8] E. Ben-Chetrit, R. I. Fox, and E. M. Tan, "Dissociation of immune responses to the SS-A (Ro) $52-\kappa \mathrm{D}$ and $60-\kappa \mathrm{D}$ polypeptides in systemic lupus erythematosus and Sjogren's syndrome," Arthritis and Rheumatism, vol. 33, no. 3, pp. 349355, 1990.

[9] M. V. Fukuda, S. C. Lo, C. S. de Almeida, and S. K. Shinjo, "Anti-Ro antibody and cutaneous vasculitis in systemic lupus erythematosus," Clinical Rheumatology, vol. 28, no. 3, pp. 301-304, 2009.

[10] E. L. Alexander, F. C. Arnett, T. T. Provost, and M. B. Stevens, "Sjogren's syndrome: association of anti-Ro(SS-A) antibodies with vasculitis, hematologic abnormalities, and serologic hyperreactivity," Annals of Internal Medicine, vol. 98, no. 2, pp. 155-159, 1983.

[11] B. T. Kurien, J. Newland, C. Paczkowski, K. L. Moore, and R. H. Scofield, "Association of neutropenia in systemic lupus erythematosus (SLE) with anti-Ro and binding of an immunologically cross-reactive neutrophil membrane antigen," Clinical and Experimental Immunology, vol. 120, no. 1, pp. 209-217, 2000.

[12] C. B. Mond, M. G. E. Peterson, and N. F. Rothfield, "Correlation of anti-Ro antibody with photosensitivity rash in systemic lupus erythematosus patients," Arthritis and Rheumatism, vol. 32, no. 2, pp. 202-204, 1989.

[13] D. P. McCauliffe, "Cutaneous diseases in adults associated with Anti-Ro/SS-A autoantibody production," Lupus, vol. 6, no. 2, pp. 158-166, 1997.

[14] R. Cimaz, D. L. Spence, L. Hornberger, and E. D. Silverman, "Incidence and spectrum of neonatal lupus erythematosus: a prospective study of infants born to mothers with anti-ro autoantibodies," Journal of Pediatrics, vol. 142, no. 6, pp. 678683, 2003.

[15] J. P. Buyon, R. M. Clancy, and D. M. Friedman, "Cardiac manifestations of neonatal lupus erythematosus: guidelines to management, integrating clues from the bench and bedside," Nature Clinical Practice Rheumatology, vol. 5, no. 3, pp. 139-148, 2009.

[16] R. W. Wilson, T. T. Provost, and W. B. Bias, "Sjogren's syndrome. Influence of multiple HLA-D region alloantigens on clinical and serologic expression," Arthritis and Rheumatism, vol. 27, no. 11, pp. 1245-1253, 1984.

[17] O. Meyer, G. Hauptmann, and G. Tappeiner, "Genetic deficiency of C4, C2 or C1q and lupus syndromes. Association with anti-Ro (SS-A) antibodies," Clinical and Experimental Immunology, vol. 62, no. 3, pp. 678-684, 1985.

[18] M. Dugar, S. Cox, V. Limaye, T. P. Gordon, and P. J. RobertsThomson, "Diagnostic utility of anti-Ro52 detection in systemic autoimmunity," Postgraduate Medical Journal, vol. 86, no. 1012, pp. 79-82, 2010.

[19] S. Salomonsson, S. E. Sonesson, L. Ottosson et al., "Ro/SSA autoantibodies directly bind cardiomyocytes, disturb calcium homeostasis, and mediate congenital heart block," Journal of Experimental Medicine, vol. 201, no. 1, pp. 11-17, 2005.

[20] M. B. Frank, K. Itoh, A. Fujisaku, P. Pontarotti, M. G. Mattei, and B. R. Neas, "The mapping of the human $52-\kappa \mathrm{D}$ Ro/SSA autoantigen gene to human chromosome II, and its polymorphisms," American Journal of Human Genetics, vol. 52, no. 1, pp. 183-191, 1993.

[21] H. Tsugu, R. Horowitz, N. Gibson, and M. B. Frank, "The location of a disease-associated polymorphism and genomic structure of the human $52-\kappa \mathrm{Da}$ Ro/SSA locus (SSA1)," Genomics, vol. 24, no. 3, pp. 541-548, 1994.

[22] B. Nakken, R. Jonsson, and A.I. Bolstad, "Polymorphisms of the Ro52 gene associate with anti-Ro 52-kd autoantibodies in patients with primary Sjögren's syndrome," Arthritis and Rheumatism, vol. 44, no. 3, pp. 638-645, 2001.

[23] T. Imanishi, A. Morinobu, N. Hayashi et al., "A novel polymorphism of the SSA1 gene is associated with anti-SSA/Ro52 autoantibody in Japanese patients with primary 
Sjögren's syndrome," Clinical and Experimental Rheumatology, vol. 23, no. 4, pp. 521-524, 2005.

[24] A. Espinosa, W. Zhou, M. Ek et al., “The Sjögren's syndromeassociated autoantigen Ro52 is an E3 ligase that regulates proliferation and cell death," Journal of Immunology, vol. 176, no. 10, pp. 6277-6285, 2006.

[25] S. Bolland and A. Garcia-Sastre, "Vicious circle: systemic autoreactivity in Ro52/TRIM21-deficient mice," Journal of Experimental Medicine, vol. 206, no. 8, pp. 1647-1651, 2009.

[26] E. K. L. Chan, J. C. Hamel, J. P. Buyon, and E. M. Tan, "Molecular definition and sequence motifs of the $52-\kappa \mathrm{D}$ component of human SS-A/Ro autoantigen," Journal of Clinical Investigation, vol. 87, no. 1, pp. 68-76, 1991.

[27] K. Itoh, Y. Itoh, and M. B. Frank, "Protein heterogeneity in the human Ro/SSA ribonucleoproteins. The 52- and $60-\kappa \mathrm{D}$ Ro/SSA autoantigens are encoded by separate genes," Journal of Clinical Investigation, vol. 87, no. 1, pp. 177-186, 1991.

[28] E. K. L. Chan, F. Di Donato, J. C. Hamel, C. E. Tseng, and J. P. Buyon, " $52-\kappa \mathrm{D}$ SS-A/Ro: genomic structure and identification of an alternatively spliced transcript encoding a novel leucine zipper-minus autoantigen expressed in fetal and adult heart," Journal of Experimental Medicine, vol. 182, no. 4, pp. 983-992, 1995.

[29] G. Bepler, K. C. O’Briant, Y. C. Kim, G. Schreiber, and D. M. Pitterle, "A 1.4-Mb high-resolution physical map and contig of chromosome segment 11p15.5 and Genes in the LOH11A metastasis suppressor region," Genomics, vol. 55, no. 2, pp. 164-175, 1999.

[30] C. L. Keech, T. P. Gordon, and J. McCluskey, "Structural differences between the human and mouse $52-\kappa \mathrm{D}$ Ro autoantigens associated with poorly conserved autoantibody activity across species," Clinical and Experimental Immunology, vol. 104, no. 2, pp. 255-263, 1996.

[31] S. Nisole, J. P. Stoye, and A. Saïb, "TRIM family proteins: retroviral restriction and antiviral defence," Nature Reviews Microbiology, vol. 3, no. 10, pp. 799-808, 2005.

[32] A. Reymond, G. Meroni, A. Fantozzi et al., "The tripartite motif family identifies cell compartments," EMBO Journal, vol. 20, no. 9, pp. 2140-2151, 2001.

[33] K. Ozato, D. M. Shin, T. H. Chang, and H. C. Morse, "TRIM family proteins and their emerging roles in innate immunity," Nature Reviews Immunology, vol. 8, no. 11, pp. 849-860, 2008.

[34] G. Meroni and G. Diez-Roux, "TRIM/RBCC, a novel class of 'single protein RING finger' E3 ubiquitin ligases," BioEssays, vol. 27, no. 11, pp. 1147-1157, 2005.

[35] O. Billaut-Mulot, C. Cocude, V. Kolesnitchenko et al., "SS-56, a novel cellular target of autoantibody responses in Sjögren syndrome and systemic lupus erythematosus," Journal of Clinical Investigation, vol. 108, no. 6, pp. 861-869, 2001.

[36] M. Takahashi, Y. Inaguma, H. Hiai, and F. Hirose, "Developmentally regulated expression of a human 'finger'-containing gene encoded by the 5' half of the ret transforming gene," Molecular and Cellular Biology, vol. 8, no. 4, pp. 1853-1856, 1988.

[37] R. Patarca, G. J. Freeman, J. Schwartz et al., "rpt-1, an intracellular protein from helper/inducer $\mathrm{T}$ cells that regulates gene expression of interleukin 2 receptor and human immunodeficiency virus type 1," Proceedings of the National Academy of Sciences of the United States of America, vol. 85, no. 8, pp. 2733-2737, 1988.

[38] A. Sabile, A. M. Meyer, C. Wirbelauer et al., "Regulation of p27 degradation and S-phase progression by Ro52 RING finger protein," Molecular and Cellular Biology, vol. 26, no. 16, pp. 5994-6004, 2006.

[39] K. Wada and T. Kamitani, "UnpEL/Usp4 is ubiquitinated by Ro52 and deubiquitinated by itself," Biochemical and Biophysical Research Communications, vol. 342, no. 1, pp. 253258, 2006.

[40] K. Wada, K. Tanji, and T. Kamitani, "Oncogenic protein UnpEL/Usp4 deubiquitinates Ro52 by its isopeptidase activity," Biochemical and Biophysical Research Communications, vol. 339, no. 3, pp. 731-736, 2006.

[41] H. J. Kong, D. E. Anderson, H. L. Chang et al., "Cutting edge: autoantigen Ro52 is an interferon inducible E3 ligase that ubiquitinates IRF-8 and enhances cytokine expression in macrophages," Journal of Immunology, vol. 179, no. 1, pp. 26-30, 2007.

[42] R. Yoshimi, T. H. Chang, H. Wang, T. Atsumi, H. C. Morse, and K. Ozato, "Gene disruption study reveals a nonredundant role for TRIM21/Ro52 in NF- $\kappa$ B-dependent cytokine expression in fibroblasts," Journal of Immunology, vol. 182, no. 12, pp. 7527-7538, 2009.

[43] A. Espinosa, V. Dardalhon, S. Brauner et al., "Loss of the lupus autoantigen Ro52/Trim21 induces tissue inflammation and systemic autoimmunity by disregulating the IL-23-Th17 pathway," Journal of Experimental Medicine, vol. 206, no. 8, pp. 1661-1671, 2009.

[44] R. Peek, G. J. M. Pruijn, A. J. W. Van der Kemp, and W. J. Van Venrooij, "Subcellular distribution of Ro ribonucleoprotein complexes and their constituents," Journal of Cell Science, vol. 106, no. 3, pp. 929-935, 1993.

[45] F. H. M. Simons, G. J. M. Pruijn, and W. J. Van Venrooij, "Analysis of the intracellular localization and assembly of Ro ribonucleoprotein particles by microinjection into Xenopus laevis oocytes," Journal of Cell Biology, vol. 125, no. 5, pp. 981-988, 1994.

[46] N. Pourmand, I. Blange, N. Ringertz, and I. Pettersson, "Intracellular localisation of the Ro $52 \kappa \mathrm{D}$ auto-antigen in HeLa cells visualised with green fluorescent protein chimeras," Autoimmunity, vol. 28, no. 4, pp. 225-233, 1998.

[47] D. A. Rhodes, G. Ihrke, A. T. Reinicke et al., "The 52000 MW Ro/SS-A autoantigen in Sjögren's syndrome/systemic lupus erythematosus (Ro52) is an interferon- $\gamma$ inducible tripartite motif protein associated with membrane proximal structures," Immunology, vol. 106, no. 2, pp. 246-256, 2002.

[48] M. Tanaka, K. Tanji, M. Niida, and T. Kamitani, "Dynamic movements of Ro52 cytoplasmic bodies along microtubules," Histochemistry and Cell Biology, vol. 133, no. 3, pp. 273-284, 2010.

[49] S. D. Der, A. Zhou, B. R. G. Williams, and R. H. Silverman, "Identification of genes differentially regulated by interferon $\alpha, \beta$, or $\gamma$ using oligonucleotide arrays," Proceedings of the National Academy of Sciences of the United States of America, vol. 95, no. 26, pp. 15623-15628, 1998.

[50] L. Strandberg, A. Ambrosi, A. Espinosa et al., "Interferon- $\alpha$ induces up-regulation and nuclear translocation of the Ro52 autoantigen as detected by a panel of novel Ro52-specific monoclonal antibodies," Journal of Clinical Immunology, vol. 28, no. 3, pp. 220-231, 2008.

[51] G. K. Geiss, M. Salvatore, T. M. Tumpey et al., "Cellular transcriptional profiling in influenza A virus-infected lung epithelial cells: the role of the nonstructural NS1 protein in the evasion of the host innate defense and its potential contribution to pandemic influenza," Proceedings of the National Academy of Sciences of the United States of America, vol. 99, no. 16, pp. 10736-10741, 2002. 
[52] J. M. Zimmerer, G. B. Lesinski, M. D. Radmacher, A. Ruppert, and W. E. Carson, "STAT1-dependent and STAT1independent gene expression in murine immune cells following stimulation with interferon-alpha," Cancer Immunology, Immunotherapy, vol. 56, no. 11, pp. 1845-1852, 2007.

[53] R. Rajsbaum, J. P. Stoye, and A. O’Garra, “Type I interferondependent and -independent expression of tripartite motif proteins in immune cells," European Journal of Immunology, vol. 38, no. 3, pp. 619-630, 2008.

[54] M. Ohlsson, R. Jonsson, and K. A. Brokstad, "Subcellular redistribution and surface exposure of the Ro52, Ro60 and La48 autoantigens during apoptosis in human ductal epithelial cells: a possible mechanism in the pathogenesis of Sjögren's syndrome," Scandinavian Journal of Immunology, vol. 56, no. 5, pp. 456-469, 2002.

[55] M. E. Miranda, C. E. Tseng, W. Rashbaum et al., "Accessibility of SSA/Ro and SSB/La antigens to maternal autoantibodies in apoptotic human fetal cardiac myocytes," Journal of Immunology, vol. 161, no. 9, pp. 5061-5069, 1998.

[56] M. E. Miranda-Carus, A. D. Askanase, R. M. Clancy et al., "Anti-SSA/Ro and anti-SSB/La autoantibodies bind the surface of apoptotic fetal cardiocytes and promote secretion of TNF- $\alpha$ by macrophages," Journal of Immunology, vol. 165, no. 9, pp. 5345-5351, 2000.

[57] W. P. LeFeber, D. A. Norris, and S. R. Ryan, "Ultraviolet light induces binding of antibodies to selected nuclear antigens on cultured human keratinocytes," Journal of Clinical Investigation, vol. 74, no. 4, pp. 1545-1551, 1984.

[58] T. Dorner, M. Hucko, W. J. Mayet, U. Trefzer, G. R. Burmester, and F. Hiepe, "Enhanced membrane expression of the $52 \kappa \mathrm{Da} \mathrm{Ro}(\mathrm{SS}-\mathrm{A})$ and $\mathrm{La}(\mathrm{SS}-\mathrm{B})$ antigens by human keratinocytes induced by TNF $\alpha$," Annals of the Rheumatic Diseases, vol. 54, no. 11, pp. 904-909, 1995.

[59] B. Wang, X. Dong, Z. Yuan, Y. Zuo, and J. Wang, "SSA/Ro antigen expressed on membrane of UVB-induced apoptotic keratinocytes is pathogenic but not detectable in supernatant of cell culture," Chinese Medical Journal, vol. 112, no. 6, pp. 512-515, 1999.

[60] J. Saegusa, S. Kawano, M. Koshiba et al., "Oxidative stress mediates cell surface expression of SS-A/Ro antigen on keratinocytes," Free Radical Biology and Medicine, vol. 32, no. 10, pp. 1006-1016, 2002.

[61] F. Furukawa, M. B. Lyons, L. A. Lee, S. N. Coulter, and D. A. Norris, "Estradiol enhances binding to cultured human keratinocytes of antibodies specific for SS-A/Ro and SS-B/La. Another possible mechanism for estradiol influence of lupus erythematosus," Journal of Immunology, vol. 141, no. 5, pp. 1480-1488, 1988.

[62] A. Espinosa, V. Oke, A. Elfving, F. Nyberg, R. Covacu, and M. Wahren-Herlenius, "The autoantigen Ro52 is an E3 ligase resident in the cytoplasm but enters the nucleus upon cellular exposure to nitric oxide," Experimental Cell Research, vol. 314, no. 20, pp. 3605-3613, 2008.

[63] E. V. Shusta, J. Y. Li, R. J. Boado, and W. M. Pardridge, "The Ro52/SS-A autoantigen has elevated expression at the brain microvasculature," NeuroReport, vol. 14, no. 14, pp. 18611865, 2003.

[64] J. P. Buyon, C. E. Tseng, F. D. I. Donato, W. Rashbaum, A. Morris, and E. K. L. Chan, "Cardiac expression of $52 \beta$, an alternative transcript of the congenital heart blockassociated 52-kd SS-A/Ro autoantigen, is maximal during fetal development," Arthritis and Rheumatism, vol. 40, no. 4, pp. 655-660, 1997.
[65] A. I. Bolstad, H. G. Eiken, B. Rosenlund, M. E. AlarcónRiquelme, and R. Jonsson, "Increased salivary gland tissue expression of Fas, Fas ligand, cytotoxic T lymphocyteassociated antigen 4, and programmed cell death 1 in primary Sjögren's syndrome," Arthritis and Rheumatism, vol. 48, no. 1, pp. 174-185, 2003.

[66] K. Wada and T. Kamitani, "Autoantigen Ro52 is an E3 ubiquitin ligase," Biochemical and Biophysical Research Communications, vol. 339, no. 1, pp. 415-421, 2006.

[67] J. Y. Kim and K. Ozato, "The sequestosome 1/p62 attenuates cytokine gene expression in activated macrophages by inhibiting IFN regulatory factor 8 and TNF receptorassociated factor 6/NF- $\kappa$ B activity," Journal of Immunology, vol. 182, no. 4, pp. 2131-2140, 2009.

[68] R. Higgs, J. N. Gabhann, N. B. Larbi, E. P. Breen, K. A. Fitzgerald, and C. A. Jefferies, "The E3 ubiquitin ligase Ro52 negatively regulates IFN- $\beta$ production post-pathogen recognition by polyubiquitin-mediated degradation of IRF3," Journal of Immunology, vol. 181, no. 3, pp. 1780-1786, 2008.

[69] K. Yang, H. X. Shi, X. Y. Liu et al., "TRIM21 is essential to sustain IFN regulatory factor 3 activation during antiviral response," Journal of Immunology, vol. 182, no. 6, pp. 37823792, 2009.

[70] R. Higgs, E. Lazzari, C. Wynne et al., "Self protection from anti-viral responses-Ro52 promotes degradation of the transcription factor IRF7 downstream of the viral Toll-like receptors," PLoS ONE, vol. 5, no. 7, Article ID e11776, 2010.

[71] J. A. Young, D. Sermwittayawong, H. J. Kim et al., "Fasassociated death domain (FADD) and the E3 ubiquitinprotein ligase TRIM21 interact to negatively regulate virusinduced interferon production," Journal of Biological Chemistry, vol. 286, no. 8, pp. 6521-6531, 2011.

[72] T. Ishii, K. Ohnuma, A. Murakami et al., "SS-A/Ro52, an autoantigen involved in CD28-mediated IL-2 production," Journal of Immunology, vol. 170, no. 7, pp. 3653-3661, 2003.

[73] J. C. Crispín, S. N. C. Liossis, K. Kis-Toth et al., "Pathogenesis of human systemic lupus erythematosus: recent advances," Trends in Molecular Medicine, vol. 16, no. 2, pp. 47-57, 2010.

[74] J. G. Routsias and A. G. Tzioufas, "Autoimmune response and target autoantigens in Sjogren's syndrome," European Journal of Clinical Investigation, vol. 40, no. 11, pp. 1026-1036, 2010.

[75] A. H. Keeble, Z. Khan, A. Forster, and L. C. James, "TRIM21 is an IgG receptor that is structurally, thermodynamically, and kinetically conserved," Proceedings of the National Academy of Sciences of the United States of America, vol. 105, no. 16, pp. 6045-6050, 2008.

[76] L. C. James, A. H. Keeble, Z. Khan, D. A. Rhodes, and J. Trowsdale, "Structural basis for PRYSPRY-mediated tripartite motif (TRIM) protein function," Proceedings of the National Academy of Sciences of the United States of America, vol. 104, no. 15, pp. 6200-6205, 2007.

[77] Y. S. Yang, B. Wang, and J. C. Weissler, "Autoantigen Ro52 directly interacts with human IgG heavy chain in vivo in mammalian cells," Molecular Immunology, vol. 37, no. 10, pp. 591-602, 2000.

[78] Y. S. Yang, T. Eversole, D. J. Lee, R. D. Sontheimer, and J. D. Capra, "Protein-protein interactions between native Ro52 and immunoglobulin G heavy chain," Scandinavian Journal of Immunology, vol. 49, no. 6, pp. 620-628, 1999.

[79] M. Takahata, M. Bohgaki, T. Tsukiyama, T. Kondo, M. Asaka, and S. Hatakeyama, "Ro52 functionally interacts with IgG1 and regulates its quality control via the ERAD system," Molecular Immunology, vol. 45, no. 7, pp. 2045-2054, 2008. 
[80] D. A. Rhodes and J. Trowsdale, "TRIM21 is a trimeric protein that binds IgG Fc via the B30.2 domain," Molecular Immunology, vol. 44, no. 9, pp. 2406-2414, 2007.

[81] J. P. Buyon, S. G. Slade, J. D. Reveille, J. C. Hamel, and E. K. L. Chan, "Autoantibody responses to the 'native' 52$\kappa \mathrm{Da} S \mathrm{SS}-\mathrm{A} /$ Ro protein in neonatal lupus syndromes, systemic lupus erythematosus, and Sjogren's syndrome," Journal of Immunology, vol. 152, no. 7, pp. 3675-3684, 1994.

[82] D. L. Mallery, W. A. McEwan, S. R. Bidgood, G. J. Towers, C. M. Johnson, and L. C. James, "Antibodies mediate intracellular immunity through tripartite motif-containing 21 (TRIM21)," Proceedings of the National Academy of Sciences of the United States of America, vol. 107, no. 46, pp. 19985 19990, 2010.

[83] W. A. Mcewan, D. L. Mallery, D. A. Rhodes, J. Trowsdale, and L. C. James, "Intracellular antibody-mediated immunity and the role of TRIM21," BioEssays, vol. 33, no. 11, pp. 803-809, 2011.

[84] M. Tanaka and T. Kamitani, "Cytoplasmic relocation of Daxx induced by Ro52 and FLASH," Histochemistry and Cell Biology, vol. 134, no. 3, pp. 297-306, 2010.

[85] K. B. Grandinetti, T. A. Stevens, S. Ha et al., "Overexpression of TRIB2 in human lung cancers contributes to tumorigenesis through downregulation of $\mathrm{C} / \mathrm{EBP} \alpha$," Oncogene, vol. 30, no. 30, pp. 3328-3335, 2011.

[86] T. Yamochi, K. Ohnuma, O. Hosono, H. Tanaka, Y. Kanai, and C. Morimoto, "SSA/Ro52 autoantigen interacts with Dcp2 to enhance its decapping activity," Biochemical and Biophysical Research Communications, vol. 370, no. 1, pp. 195-199, 2008.

[87] Z. Tatari-Calderone, C. P. Minniti, T. Kratovil et al., "rs660 polymorphism in Ro52 (SSA1; TRIM 21) is a marker for agedependent tolerance induction and efficiency of alloimmunization in sickle cell disease," Molecular Immunology, vol. 47, no. 1, pp. 64-70, 2009.

[88] S. R. Patel, J. E. Hendrickson, N. H. Smith et al., "Alloimmunization against RBC or PLT antigens is independent of TRIM21 expression in a murine model," Molecular Immunology, vol. 48, no. 6-7, pp. 909-913, 2011.

[89] A. Espinosa, J. Hennig, A. Ambrosi et al., "Anti-Ro52 autoantibodies from patients with Sjögren's syndrome inhibit the Ro52 E3 ligase activity by blocking the E3/E2 interface," Journal of Biological Chemistry, vol. 286, no. 42, pp. 3647836491, 2011.

[90] K. Wada, M. Niida, M. Tanaka, and T. Kamitani, "Ro52mediated monoubiquitination of IKK $\beta$ down-regulates NF$\kappa \mathrm{B}$ signalling," Journal of Biochemistry, vol. 146, no. 6, pp. 821-832, 2009.

[91] M. Niida, M. Tanaka, and T. Kamitani, "Downregulation of active IKK $\beta$ by Ro52-mediated autophagy," Molecular Immunology, vol. 47, no. 14, pp. 2378-2387, 2010.

[92] K. Ozato, R. Yoshimi, T.-H. Chang, H. Wang, T. Atsumi, and H. C. Morse III, "Comment on 'gene disruption study reveals a nonredundant role for TRIM21/Ro52 in NF- $\kappa$ B-dependent cytokine expression in fibroblasts', Journal of Immunology, vol. 183, no. 12, p. 7619, 2009.

[93] A. Espinosa, S. Brauner, A. Ambrosi, V. Kuchroo, and M. Wahren-Herlenius, "Response to comment on 'gene disruption study reveals a nonredundant role for TRIM21/Ro52 in NF- $\kappa \mathrm{B}$-dependent cytokine expression in fibroblasts," Journal of Immunology, vol. 183, no. 12, pp. 7620-7621, 2009.

[94] E. C. Baechler, F. M. Batliwalla, G. Karypis et al., "Interferoninducible gene expression signature in peripheral blood cells of patients with severe lupus," Proceedings of the National Academy of Sciences of the United States of America, vol. 100, no. 5, pp. 2610-2615, 2003.

[95] Y. J. Liu, "IPC: professional type 1 interferon-producing cells and plasmacytoid dendritic cell precursors," Annual Review of Immunology, vol. 23, pp. 275-306, 2005.

[96] M. K. Crow, "Type I interferon in systemic lupus erythematosus," Current Topics in Microbiology and Immunology, vol. 316, pp. 359-386, 2007.

[97] L. Farkas, K. Beiske, F. Lund-Johansen, P. Brandtzaeg, and F. L. Jahnsen, "Plasmacytoid dendritic cells (natural interferon$\alpha / \beta$-producing cells) accumulate in cutaneous lupus erythematosus lesions," American Journal of Pathology, vol. 159, no. 1, pp. 237-243, 2001.

[98] V. Pascual, L. Farkas, and J. Banchereau, "Systemic lupus erythematosus: all roads lead to type I interferons," Current Opinion in Immunology, vol. 18, no. 6, pp. 676-682, 2006.

[99] L. E. Wilson, D. Widman, S. H. Dikman, and P. D. Gorevic, "Autoimmune disease complicating antiviral therapy for hepatitis C virus infection," Seminars in Arthritis and Rheumatism, vol. 32, no. 3, pp. 163-173, 2002.

[100] P. P. Tak and G. S. Firestein, "NF- $\kappa$ B: a key role in inflammatory diseases," Journal of Clinical Investigation, vol. 107, no. 1, pp. 7-11, 2001.

[101] L. Zheng, R. Sinniah, and S. I. H. Hsu, "In situ glomerular expression of activated NF- $\kappa \mathrm{B}$ in human lupus nephritis and other non-proliferative proteinuric glomerulopathy," Virchows Archiv, vol. 448, no. 2, pp. 172-183, 2006.

[102] J. C. Crispin, M. Oukka, G. Bayliss et al., "Expanded double negative $\mathrm{T}$ cells in patients with systemic lupus erythematosus produce IL-17 and infiltrate the kidneys," Journal of Immunology, vol. 181, no. 12, pp. 8761-8766, 2008.

[103] Z. Zhang, V. C. Kyttaris, and G. C. Tsokos, "The role of IL23/IL-17 axis in lupus nephritis," Journal of Immunology, vol. 183, no. 5, pp. 3160-3169, 2009.

[104] R. J. Looney, J. H. Anolik, D. Campbell et al., "B cell depletion as a novel treatment for systemic lupus erythematosus: a phase I/II dose-escalation trial of rituximab," Arthritis and Rheumatism, vol. 50, no. 8, pp. 2580-2589, 2004.

[105] M. Ramos-Casals, M. J. Soto, M. J. Cuadrado, and M. A. Khamashta, "Rituximab in systemic lupus erythematosus A systematic review of off-label use in 188 cases," Lupus, vol. 18, no. 9, pp. 767-776, 2009.

[106] T. Y. T. Lu, K. P. Ng, G. Cambridge et al., "A retrospective seven-year analysis of the use of B cell depletion therapy in systemic lupus erythematosus at university college london hospital: the first fifty patients," Arthritis Care and Research, vol. 61, no. 4, pp. 482-487, 2009.

[107] J. T. Merrill, C. M. Neuwelt, D. J. Wallace et al., "Efficacy and safety of rituximab in moderately-to-severely active systemic lupus erythematosus: the randomized, double-blind, phase II/III systemic lupus erythematosus evaluation of rituximab trial," Arthritis and Rheumatism, vol. 62, no. 1, pp. 222-233, 2010.

[108] S. V. Navarra, R. M. Guzmán, A. E. Gallacher et al., "Efficacy and safety of belimumab in patients with active systemic lupus erythematosus: a randomised, placebo-controlled, phase 3 trial," The Lancet, vol. 377, no. 9767, pp. 721-731, 2011.

[109] T. Kishimoto and T. Hirano, "Molecular regulation of B lymphocyte response," Annual Review of Immunology, vol. 6, pp. 485-512, 1988. 
[110] G. G. Illei, Y. Shirota, C. H. Yarboro et al., “Tocilizumab in systemic lupus erythematosus: data on safety, preliminary efficacy, and impact on circulating plasma cells from an open-label phase I dosage-escalation study," Arthritis and Rheumatism, vol. 62, no. 2, pp. 542-552, 2010.

[111] K. Yamauchi, K. Wada, K. Tanji, M. Tanaka, and T. Kamitani, "Ubiquitination of E3 ubiquitin ligase TRIM $5 \alpha$ and its potential role," FEBS Journal, vol. 275, no. 7, pp. 1540-1555, 2008 . 


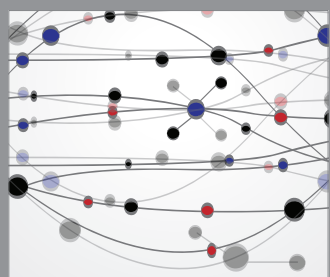

The Scientific World Journal
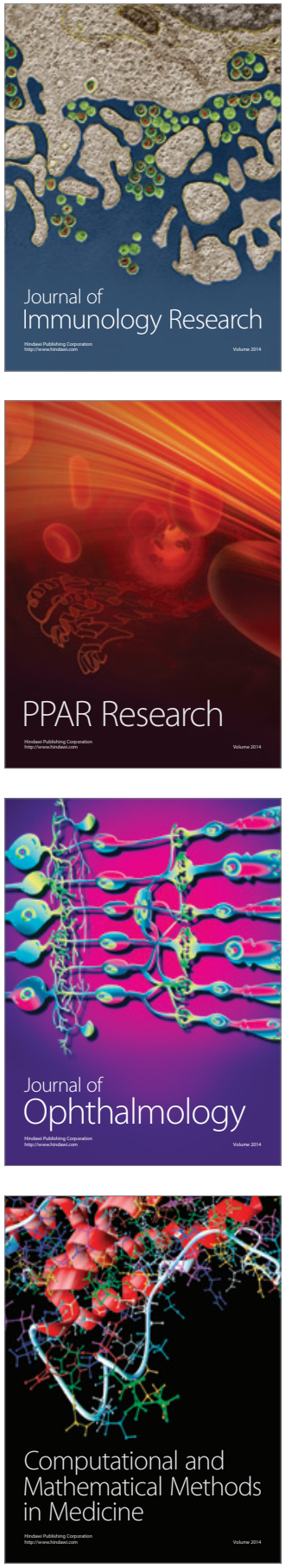

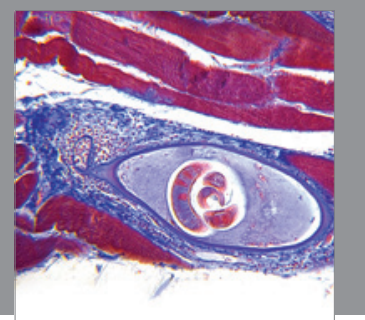

Gastroenterology

Research and Practice
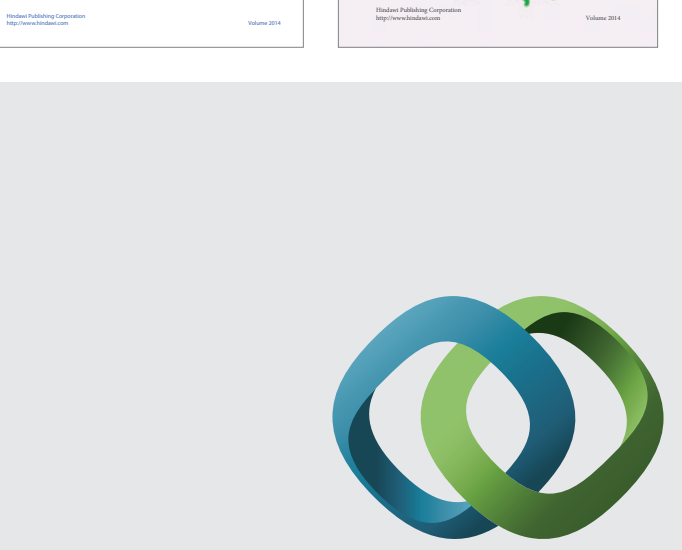

\section{Hindawi}

Submit your manuscripts at

http://www.hindawi.com
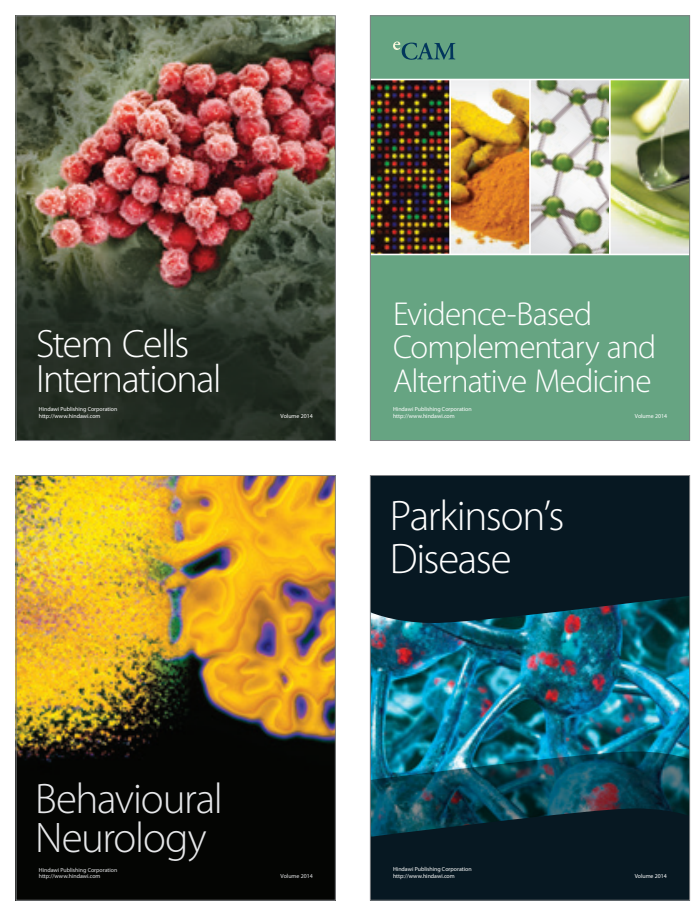

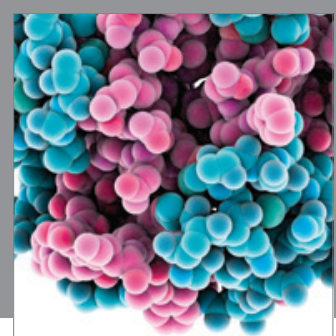

Journal of
Diabetes Research

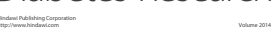

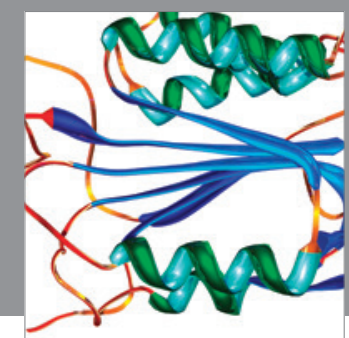

Disease Markers
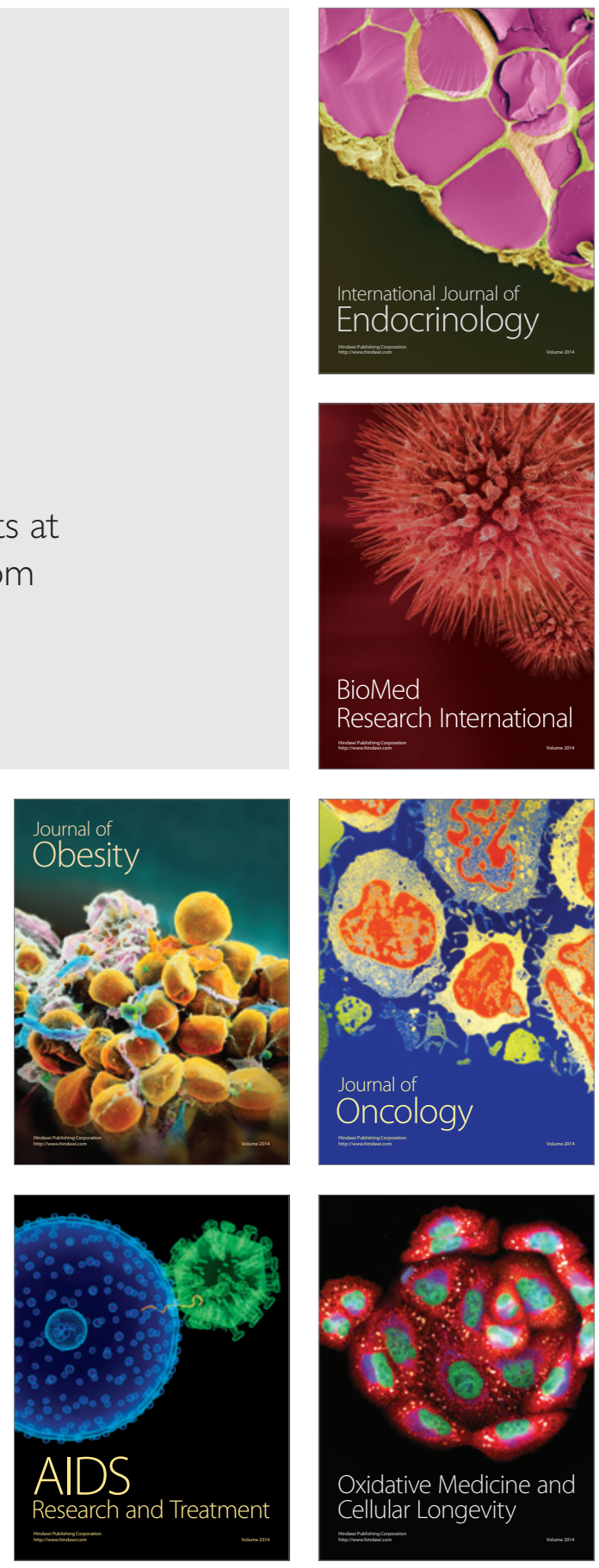